\title{
Study of socio-demographic and treatment profile and other epidemiological correlates of clients attending revised national tuberculosis control programme clinic in a tertiary hospital of West Bengal, India
}

\author{
Subha Sankha Kundu, Rajib Sikder, Rituraj Dey, Kunal Kanti Majumdar*, Gautam Joardar
}

Department of Community Medicine, KPC Medical College and Hospital, Kolkata, West Bengal, India

\author{
Received: 11 August 2019 \\ Revised: 02 January 2020 \\ Accepted: 03 January 2020 \\ *Correspondence: \\ Dr. Kunal Kanti Majumdar, \\ E-mail: kunalmajumdar1@gmail.com
}

Copyright: (c) the author(s), publisher and licensee Medip Academy. This is an open-access article distributed under the terms of the Creative Commons Attribution Non-Commercial License, which permits unrestricted non-commercial use, distribution, and reproduction in any medium, provided the original work is properly cited.

\begin{abstract}
Background: Tuberculosis (TB) is an infectious disease caused by Mycobacterium tuberculosis bacteria spread by droplet infection. According to global TB report 2017, there were approximately 28 lakhs cases of TB in India accounting a quarter of the world TB cases. Today, it is the fastest-expanding and the largest program in the world in terms of patients initiated on treatment and the second largest in terms of population coverage. The objective of this study is to assess the socio-demographic profile of the patients attending revised national TB control programme (RNTCP) clinic, to determine the nature of disease, its co-morbidities, seasonal variability and treatment profile of the patients attending the RNTCP clinic during this study period.

Methods: This was a retrospective record-based study conducted in RNTCP clinic of KPC Medical College and Hospital, Kolkata. Details of all the 684 patients who were enrolled under RNTCP from the year 2014 to 2018 were collected from RNTCP records. Data was analyzed using suitable software.

Results: 684 cases were registered and treated under directly observed treatment, short-course (DOTS) during the study period with $41 \%$ completing treatment. $84.3 \%$ were new TB cases. $23.61 \%$ were sputum smear positive. Males $(67.25 \%)$ contributed to more in cases. Maximum patients visited during March to June. $74.87 \%$ of the total patients were diagnosed with pulmonary TB. Pleural effusion was the commonest form of extrapulmonary TB (42.75\%).

Conclusions: The number of TB cases showed a decreasing trend over the years. Males contributed to a greater number of cases with majority being contributed by the age group 21-30 years.
\end{abstract}

Keywords: Socio-demography, Tuberculosis, RNTCP, Seasonal variability, Co-morbidities

\section{INTRODUCTION}

Tuberculosis (TB) is an infectious disease usually caused by Mycobacterium tuberculosis (MTB) spread by droplet infection. ${ }^{1}$ It generally affects the lungs, but can also affect other parts of the body characterized by chronic cough with blood-containing mucus, fever, night sweats, and weight loss. If left untreated, each person with active TB disease will infect on an average between 10 and 15 people every year and this continues the transmission of Tuberculosis. ${ }^{1}$

TB is one of the top 10 causes of death worldwide and is the leading killer of human immunodeficiency virus (HIV) positive people. In 2017, 10 million people were affected with TB, of which 1.6 million died from the 
disease (including 0.3 million among people with HIV) and an estimated 1 million children were infected with TB of which 2.3 lakhs children died of TB (including children with HIV associated TB). Globally, TB incidence is falling at about $2 \%$ per year which needs to be accelerated to a 4-5\% annual decline to reach the 2020 milestones of the end TB strategy. Ending the TB epidemic by 2030 has become one of the health targets of the sustainable development goals. ${ }^{2}$

India has the highest burden of TB globally, accounting for one fifth of the global incidence and two thirds of the cases in South-East Asia. ${ }^{3}$ In India, approximately 27.40 lakhs $(0.20 \%)$ people suffered from Tuberculosis in 2017 of which around $86,000(3.14 \%)$ had co-infection with HIV. ${ }^{4}$ Still now it is one of the major health problems and causes of morbidity and mortality in developing countries even after being one of the oldest diseases known to humanity. In India, TB still has a social stigma associated with it despite continuous efforts by the government leaving its aftermath physically, culturally, and intellectually on the affected patients and their families.

Many of these people live in the world's poorest, most vulnerable communities or are among marginalized populations such as migrant workers, refugees, internally displaced persons, prisoners, indigenous peoples, ethnic minorities and drug users and they are more susceptible to tuberculosis than the general population. Tuberculosis affects the productive age group the most and the resultant economic cost for society is high. Despite the fact that million have been spent till now to uproot this disease it is absolutely clear that reaching the unreached millions in need of TB diagnosis and care requires accessible laboratory facilities with quality services and effective anti-tuberculosis drugs, but this isn't enough as we need more than medical treatment to conquer this evil of the society.

It is well known that the incidence of many respiratory infections shows seasonal variation, and it is much less well documented for tuberculosis (TB). ${ }^{5}$ In the preantibiotic era, the TB mortality rate was higher in late winter and early spring than that any other time of the year. Although the exact mechanism underlying the fluctuation of tuberculosis in a particular time of the year is still not clear, several researchers have suggested that the environmental and social factors such as temperature, humidity, sunlight, as well as crowding and person-toperson contacts, are a source of TB seasonality, particularly, in winter time. ${ }^{6}$ This explanation applies to primary or re-infection TB, but not to reactivation TB. To explain the seasonal trend of both reactivation and primary $\mathrm{TB}$, it is usual to consider that the main cause of TB seasonality is intrinsic. ${ }^{7} \mathrm{~A}$ possible link between vitamin D deficiency and impaired host-defense to MTB infection leading to primary TB has been postulated. ${ }^{8}$ Moreover, significant seasonal vitamin D variations were observed in several communities, and reveal that variation of values for 25-hydroxy vitamin D decreases in spring and winter. Immune system competencies vary through the year with significant periodicity in cell function, proliferation, and percentage or number of peripheral blood leukocytes subsets. For example, the level of $\mathrm{B}$ lymphocytes in the peripheral blood has been shown to vary throughout the year, being lower in winter than in summer. ${ }^{7}$ The absolute number of CD4+ T lymphocytes is the lowest in summer when the level of CD8+ $\mathrm{T}$ lymphocytes is the highest. ${ }^{7}$ The seasonal variability of TB notification may reflect the seasonality of vitamin D and human immunity or may be caused by the influence of seasons on human activity. However, these questions related to seasonality of tuberculosis remain controversial.

The objective of the current study was to determine the socio demographic profile of the TB patients registered under revised national TB control programme (RNTCP) in a Tertiary Centre of Kolkata, West Bengal, to determine the nature of disease, its co-morbidities and treatment profile of the patients attending the RNTCP clinic during this study period and to find out the seasonal variability of the disease.

\section{METHODS}

\section{Study period}

The study was conducted over a time period of 1 month, from $1^{\text {st }}$ January 2019 to $31^{\text {st }}$ January 2019, a total duration of 31 days.

\section{Study design}

It was a retrospective cross-sectional study based on the analysis of hospital records. The study was conducted in the RNTCP unit of a Tertiary Care Hospital in South 24 Parganas district of West Bengal. Study population included were individuals who attended the RNTCP clinic in the 5 years (January 2014 to December 2018) and registered for treatment under directly observed treatment, short-course (DOTS) program of RNTCP.

A total of 684 patients were registered. The data collection was done using RNTCP records (treatment cards and TB registers) which are meticulously maintained in the RNTCP clinic. Socio-demographic profile of TB patients, family history, type of TB for which the patient was treated, duration of therapy, documented treatment outcome, HIV and diabetes mellitus prevalence among the enrolled patients and seasonal fluctuations were extracted from the RNTCP records. The data was collected and entered using Excel worksheet Data was analyzed using suitable statistical methods and available software. Statistical method used was simple arithmetical calculations. 


\section{Study tool}

Indoor and outpatient department (OPD) records of RNTCP unit of tertiary medical college.

\section{Study variables}

Cases, treatment status, treatment outcomes, diagnostic tools, socio-demographic profiles of the cases, type of tuberculosis, any associated co-morbidities.

\section{Inclusion criteria}

All patients who registered with the RNTCP unit during the period of January 2014 to December 2018 were included.

\section{Exclusion criteria}

The patients who registered beyond December 2018 period were excluded.

The study was conducted after obtaining permission from the Institutional Ethical Committee.

\section{RESULTS}

A total of 684 patients were enrolled and received treatment in the past 5 years i.e., from January 2014 to December 2018. Of them, 639 had their complete treatment record while 45 had their treatment ongoing.

Of the total 684 patients, $460(67.25 \%)$ were males and $224(32.75 \%)$ were females (Figure 1).

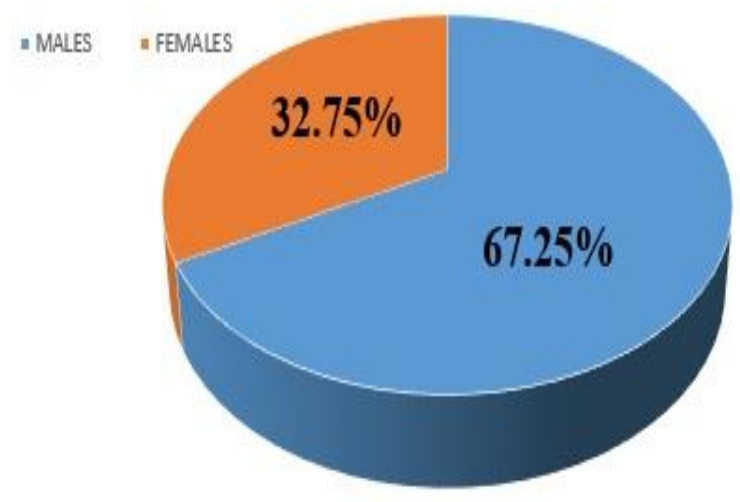

Figure 1: Distribution of patients according to gender.

The number of patients attending the RNTCP clinic declined each year with 148 patients in 2014, 140 in 2015, 136 in 2016, 132 in 2017 and 128 in 2018. A total of $13.51 \%$ decline over 5 years (Figure 2 ).

The patients were contributed mostly be the productive age group i.e., 21-30 years (21.49\%) followed by 31-40 years $(18.86 \%)$ and the least by the age group of $1-10$ years $(1.17 \%)$ (Table 1$)$.

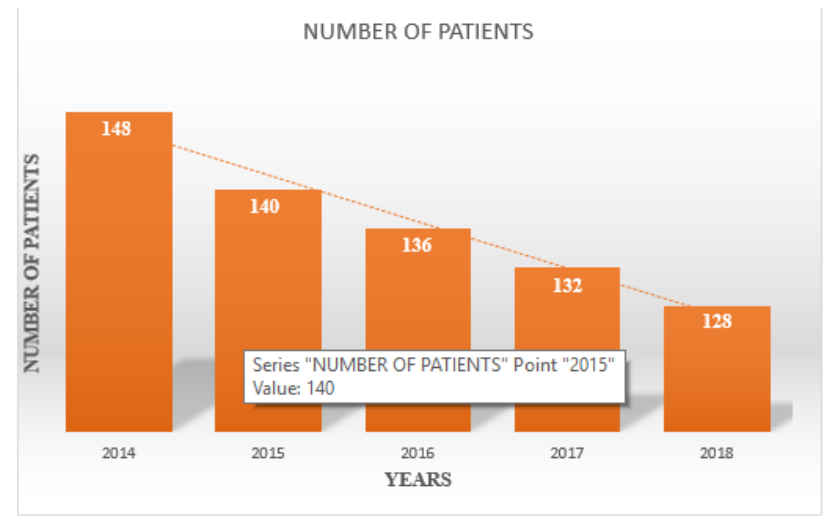

Figure 2: Downward trend of patients over the 5 years.

Table 1: Age-wise distribution.

\begin{tabular}{|lll|}
\hline Age (yrs) & $\mathbf{N}$ & $\%$ \\
\hline $\mathbf{1 - 1 0}$ & 8 & 1.17 \\
\hline $\mathbf{1 1 - 2 0}$ & 61 & 8.92 \\
\hline $\mathbf{2 1 - 3 0}$ & 147 & 21.49 \\
\hline $\mathbf{3 1 - 1 0}$ & 129 & 18.86 \\
\hline $\mathbf{4 1 - 5 0}$ & 113 & 16.52 \\
\hline $\mathbf{5 1 - 6 0}$ & 105 & 15.35 \\
\hline $\mathbf{6 1 - 7 0}$ & 73 & 10.67 \\
\hline $\mathbf{7 1 - 8 0}$ & 35 & 5.12 \\
\hline $\mathbf{8 1 - 9 0}$ & 13 & 1.90 \\
\hline
\end{tabular}

$284(41.52 \%)$ patients were from urban slum while 216 $(31.57 \%)$ were from rural areas and 184 (26.90\%) from remaining urban areas.

Maximum patients visited during the months of March to June, i.e., the spring and summer season while they were in least number in the months of December to January i.e., the winter months (Table 2).

Table 2: Month wise distribution of patients in 5 years.

\begin{tabular}{|llllll|}
\hline Months & $\mathbf{2 0 1 4}$ & $\mathbf{2 0 1 5}$ & $\mathbf{2 0 1 6}$ & $\mathbf{2 0 1 7}$ & $\mathbf{2 0 1 8}$ \\
\hline January & 9 & 10 & 8 & 10 & 8 \\
\hline February & 10 & 9 & 9 & 10 & 8 \\
\hline March & 17 & 19 & 17 & 16 & 16 \\
\hline April & 19 & 19 & 16 & 14 & 16 \\
\hline May & 18 & 17 & 16 & 14 & 18 \\
\hline June & 18 & 18 & 16 & 15 & 15 \\
\hline July & 10 & 10 & 11 & 10 & 9 \\
\hline August & 11 & 9 & 9 & 8 & 8 \\
\hline September & 10 & 8 & 10 & 10 & 8 \\
\hline October & 7 & 6 & 9 & 8 & 6 \\
\hline November & 10 & 8 & 7 & 9 & 7 \\
\hline December & 9 & 7 & 8 & 8 & 9 \\
\hline
\end{tabular}


Of the 684 patients, $577(84.35 \%)$ were new TB cases whereas $107(15.65 \%)$ were previously treated.

Of these 577 new TB patients, 432 (74.87\%) patients were suffering from pulmonary tuberculosis whereas 145 $(25.12 \%)$ patients suffered from extra-pulmonary tuberculosis. Of the 432 new pulmonary tuberculosis, 102 (23.61\%) were found to be sputum smear positive, rest were started on anti-tubercular drugs (ATD) based on clinical and radiographic evidences. Of the 145 extra pulmonary tuberculosis cases, 62 (42.75\%) were suffering from pleural effusion, while $20(13.79 \%)$ were diagnosed with Pott's tuberculosis; 10 (6.89\%) suffered from tuberculous meningitis, $10(6.89 \%)$ were suffering from tubercular peritonitis, $34(23.45 \%)$ were suffering from tubercular lymphadenitis and 9 (6.20\%) had cutaneous TB.

Among 107 previously treated cases, 68 (63.55\%) were relapse cases while $24(22.43 \%)$ were treatment defaulters and $15(14.02 \%)$ were treatment failure. Of these 107 category 2 patients, 80 (74.76\%) were pulmonary while 27 (25.23\%) suffered from extra pulmonary tuberculosis of which $13(48.14 \%)$ had pleural effusion, $4(14.81 \%)$ each in Pott's tuberculosis and tubercular lymphadenitis, 2 (7.4\%) each in tubercular peritonitis, tubercular meningitis and cutaneous tuberculosis.

Of the total 684 patients, $294(43 \%)$ were also suffering from diabetes mellitus, $15(2 \%)$ were HIV positive and 5 $(0.73 \%)$ were suffering from both diabetes mellitus and HIV.

All 684 (100\%) patients had chest X-ray done during their first visit. Sputum examination was done for 684 $(100 \%)$ patients of which $138(20.17 \%)$ had sputum smear positive. ADA (Adenosine De Aminase) value was found out of 102 patients $(14.91 \%)$ and were found to be of high values in all the cases. $53(7.75 \%)$ had fine needle aspiration cytology done while Mantoux test was performed on 330 (48.24\%) patients. LFT (liver function test) was performed for all the patients before starting of ATD. Screening for diabetes mellitus and HIV was done for all the patients in their first visit.

Of the 684 patients, by December 2018, record of complete treatment profile was available for 639 patients $(93.42 \%)$. Of these, $262(41 \%)$ completed treatment, 349 $(54.61 \%)$ were transferred out. $12(1.87 \%)$ expired during the course of treatment, $10(1.56 \%)$ were withdrawn from the DOTS while $6(0.96 \%)$ failed to complete their treatment.

Out of 684 patients, 295 (43.04\%) belonged to the key population while the rest were from general population. Out of the key population, 95 patients $(13.89 \%)$ had a previous contact with TB, 10 of them $(1.46 \%)$ were prison inmates, $12(1.75 \%)$ were miners, $43(6.29 \%)$ were migrants and $76(11.11 \%)$ were health care workers.

\section{DISCUSSION}

In the present study, the number of TB cases showed a declining trend over the past 5 years. Also, the maximum number of patients in any year of the study period is also less compared to a hospital-based study in West Bengal where 365 patients were registered in the RNTCP clinic in year 2011. ${ }^{9}$ In another study in south India, 289 patients enrolled in RNTCP Mukkam, Calicut. ${ }^{10}$

Most of the subjects in the present study were male $(67.25 \%)$. Similar observations were found in studies conducted by Jethani et al, Sumana et al, Sunderam et al and Christian et al where percentage of male patients were $74.8 \%, 70.5 \%, 71.1 \%$ and $68 \%$ respectively. ${ }^{11-14}$ This finding is in accordance with the statement that TB is more prevalent among male than female. ${ }^{15}$

In the present study, the patients were contributed mostly be the productive age group i.e., 21-30 years (21.49\%) followed by $31-40$ years (18.86\%). Studies reported by Sumana et al and Jethani et al revealed most of the subjects were from the age group of 25-44 years $(47.5 \%)$ and $40-49$ years $(18.7 \%)$ respectively. ${ }^{16,17}$ This was also similar to the study done by Roy et al where $27.84 \%$ of study population was in age group of 25-35 years. ${ }^{18}$ This shows that TB mainly infects the productive age group constituting to a strong economic burden and affect their work in the state.

In the present study, $41.52 \%$ were from urban slum compared to $31.57 \%$ were from rural areas. Similar results were found in the study by Manjusha et al in a tertiary care hospital of Maharashtra, India. ${ }^{19}$ This finding was also consistent with the study by Ratnesh et al at Bareilly district. $^{20}$

In the current study, $577(84.35 \%)$ were new TB cases whereas $107(15.65 \%)$ were previously treated. This was almost similar to the study by Rohit et al conducted at DTC Rewa of Central India but in sharp contrast to the study conducted by Gabriel et al at Indore. ${ }^{22}$

In the current study, $2 \%$ had HIV co-infection with Tuberculosis which was quite less as estimated $5.7 \%$ by WHO. ${ }^{23}$ This was similar to the studies obtained from 15 surveyed districts in India, 2007. ${ }^{24}$ Also in the current study, $43 \%$ were suffering from Diabetes Mellitus which was quite high compared to a study by Mohan $\mathrm{V}$ et al. in 2009 and similar studies in Pondicherry. ${ }^{25-29}$

In the present study, approximately $74 \%$ had pulmonary TB. However, Dey et al in their study mentioned pulmonary cases being $89.3 \%$ and extra-pulmonary as $10.7 \% .^{30}$

The seasonal pattern of TB is predominant during the spring and summer seasons mainly in the months from March to June. In a previous study conducted in India on 
assessment of seasonal trends Thorpe et al. reported that diagnosis of TB peaked between April and June and reached nadir between October and December. ${ }^{31}$

$41 \%$ of the patients completed their treatment which was quite high compared to $16.7 \%$ in the study conducted by Karanjekar et al. ${ }^{32}$

In our study, $1.87 \%$ expired during the course of treatment, $1.56 \%$ were withdrawn from the DOTS while $60.96 \%$ failed to complete their treatment. When compared to our study treatment outcome was poor in a study done by Moharana et al..$^{33}$

In the current study, of the total 172 extra pulmonary cases $43.60 \%$ were suffering from Pleural Effusion, while $13.95 \%$ were diagnosed with Pott's tuberculosis; $6.97 \%$ suffered from tuberculous meningitis, $6.97 \%$ were suffering from tubercular peritonitis, $22.09 \%$ were suffering from tubercular lymphadenitis and $6.39 \%$ had cutaneous TB. The results were consistent with the study conducted by Chennaveerappa et al in South India. ${ }^{34}$

\section{CONCLUSION}

A total of 684 cases were registered and treated under directly observed treatment short-course (DOTS) during the study period with decreasing number of cases being registered in each year. $84.3 \%$ were new TB cases. $23.61 \%$ were found to be sputum smear positive. Males $(67.25 \%)$ contributed to a greater number of cases. Majority were contributed by the age group between 2130 years $(21.49 \%)$. Maximum patients visited during the months of March to June, i.e., the spring and summer season. Majority of the patients $(41.52 \%)$ were from urban slum. $74.87 \%$ of the total patients were diagnosed with pulmonary tuberculosis. $43 \%$ were suffering from diabetes mellitus and $2 \%$ were HIV positive. $0.73 \%$ were suffering from both diabetes mellitus and HIV. $41 \%$ of the total patients completed treatment. Pleural effusion was the commonest form of extra-pulmonary tuberculosis (EPTB) $(42.75 \%)$.

The present study, conducted at the RNTCP clinic of $\mathrm{KPCMCH}$, was based on secondary data analysis of RNTCP. Data regarding sputum conversion after 3 and 6 months, housing standards pf the patients, their education and socio-economic status, reasons for treatment withdrawal and failure and diagnostic procedure in extra pulmonary TB were missing. Thus, emphasis should be given on proper record maintenance.

Awareness generation and proper counseling on TB-HIV co-infection among all the patients should be focused on to ensure $100 \%$ cross-referral between ICTC and RNTCP for diagnostic and treatment services. More awareness campaign is necessary to increase the number of patients visiting RNTCP clinic to facilitate early diagnosis and treatment to decrease TB death.
Funding: No funding sources

Conflict of interest: None declared

Ethical approval: The study was approved by the Institutional Ethics Committee

\section{REFERENCES}

1. Tuberculosis Fact sheet $\mathrm{N}^{\circ} 104$. WHO; 2019.

2. Available at: https://www.who.int/news-room/factsheets/detail/tuberculosis. Accessed on 30 June 2019.

3. Kishore J. National health programs of India: national policies and legislations related to health. 7th Edition. 2019: 168.

4. Available at: https://www.tbfacts.org/tb-statistics/. Accessed on 30 June 2019.

5. Thorpe LE, Frieden TR, Laserson KF, Wells C, Khtri GR. Seasonality of tuberculosis in India: Is it real and what does it tell us? Lancet. 2004;364:1613-4.

6. Nagayama N, Ohmori M. Seasonality in various forms of tuberculosis. Int $\mathrm{J}$ Tuber Lung Dis. 2006;10:1117-22.

7. Maes M, Stevens W, Scharpe S, Bosmans E, De Meyer F, Dhondt P, et al. Seasonal variation in peripheral blood leukocyte subsets and in serum interleukin-6, and soluble interleukin-2 and -6 receptor concentrations in normal volunteers. Experientia. 1994;50:821-9.

8. Davies PD. A possible Link between Vitamin D deficiency and impaired host defence to Mycobacterium Tuberculosis. Tubercle. 1985;66:301-6.

9. Chatterjee C, Singh R, Basu G, Mukhopadhyay K, Deb T, Sengupta D. Status of RNTCP in a tuberculosis unit of West Bengal. National Med J India. 2012;25(1):51.

10. Mohandas B, Pawar AT, John A, Kumar D. Treatment outcome of tuberculosis patients treated under DOTS in Calicut. Int $\mathrm{J}$ Community Med Public Health. 2017;4(5):1479-82.

11. Jethani S, Kakkar R, Semwal J, Rawat J. Sociodemographic Profile of Tuberculosis Patient : A Hospital Based Study at Dehradun. Nat J Com Med. 2014;5(1):6-9

12. Sumana M, Sreelatha CY, Renuka M, Ishwaraprasad GD. Patient and health system delays in diagnosis and treatment of tuberculosis patients in an urban tuberculosis unit of south India. Int J Community Med Public Health. 2016;3:796-804.

13. Sunderam S, Kumari S, Haider S, Kashyap V, Singh S. A study on socio demographic profile of patients having cough of two weeks or, more along with their smear microscopy outcome attending a Tertiary Care Hospital of Jharkhand, India. IJIMS. 2015;2(5):119-27.

14. Christian D, Singh US, Mukherjee S, Sharma D. Socio-demographic profiles of the delayed diagnosed patients in RNTCP, Anand District. Healthline. 2010;1(1):45-8 
15. Park K. Park's Textbook of Preventive and Social Medicine. Tuberculosis. Epidemiology of Communicable Diseases. 23rd Ed. Jabalpur: Bhanot publishers; 2017.

16. Jethani S, Kakkar R, Semwal J, Rawat J. Sociodemographic Profile of Tuberculosis Patient : A Hospital Based Study at Dehradun. Nat J Com Med. 2014;5(1):6-9

17. Sumana M, Sreelatha CY, Renuka M, Ishwaraprasad GD. Patient and health system delays in diagnosis and treatment of tuberculosis patients in an urban tuberculosis unit of south India. Int $\mathbf{J}$ Community Med Public Health. 2016;3:796-804.

18. Roy N, Basu M, Das S, Mandal A, Dutt D, Dasgupta S. Risk factors associated with default among tuberculosis patients in Darjeeling district of West Bengal, India. J Family Med Primary Care. 2015;4:3.

19. Sajith M, Thomas A, Kothia JJ, Chandrakar B, Bargaje MD. Socio-Demographic characteristics of tuberculosis patients in a tertiary care hospital. Int $\mathbf{J}$ Med Health Res. 2015:1:25-8.

20. Ratnesh, Singh AK, Gupta SB. Socio demographic profile of tuberculosis patients under RNTCP in district Bareilly. Indian J Forensic Comm Med. 2017;4(1):46-8.

21. Trivedi R, Niranjan A, Adhikari P, Pawan. Sociodemographic profile and outcome of TB patients registered at DTC Rewa of Central India. Indian J Tuberculosis. 2018;65(2):140-4.

22. Daske G, Waskel B, Shivram G, Jain S, Sharma S, Rangwala S. A cross sectional study to determine the effectiveness and compliance of the new guidelines of RNTCP. JMSCR. 2019;7(7):48-50.

23. Global tuberculosis report 2014. Geneva, World Health Organization, 2014. Available at: http://www.who.int/tb/ publications /global_report/en/. Accessed on 01 March 2019.

24. Raizada N, Chauhan LS, Khera A, Sokhey J, Wares DF, Sahu S, et al. HIV Seroprevalence among Tuberculosis Patients in India, 2006-2007. J Pone. 2008.

25. Mohan V, Pradeepa R. Epidemiology of diabetes in different regions of India. Health Administrator. 2009;22:1-18.

26. Purty AJ, Vedapriya DR, Bazroy J, Gupta S, Cherian J, Vishwanathan $M$. Prevalence of diagnosed diabetes in an urban area of Puducherry, India: Time for preventive action. Int $\mathrm{J}$ Diabetes Dev Ctries. 2009;29:6-11.

27. Gupta SK, Singh Z, Purty AJ, Vishwanathan M. Diabetes prevalence and its risk factors in urban Puducherry. Int $\mathbf{J}$ Diabetes Dev Ctries. 2009;29:166-9.

28. Bharati DR, Pal R, Kar S, Rekha R, Yamuna TV, Basu M. Prevalence and determinants of diabetes mellitus in Puducherry, South India. J Pharm Bioallied Sci. 2011;3:513-8.

29. Majgi SM, Soudarssanane BM, Roy G, Das AK. Risk factors of diabetes mellitus in rural Puducherry. Online J Health Allied Sci. 2012;11:4.

30. Dey D, Patra BC, Ghosh D. HIV seroprevalence among Tuberculosis patients in East Midnapore district of West Bengal, India. Int J Curr Res. 2015;7(5):15582-5.

31. Thorpe LE, Frieden TR, Laserson KF, Wells C, Khtri GR. Seasonality of tuberculosis in India: Is it real and what does it tell us? Lancet. 2004;364:1613-4.

32. Karanjekar VD, Lokare PO, Gaikwad AV, Doibale MK, Gujrathi VV, Kulkarni AP. Treatment Outcome and Follow-up of Tuberculosis Patients Put on Directly Observed Treatment Short-course Under Rural Health Training Center, Paithan, Aurangabad in India. Ann Med Health Sci Res. 2014;4(2):222-6.

33. Moharana PR, Satapathy DM, Sahani NC. An analysis of treatment outcome among TB patients put under dots at a tertiary level health facility of Orissa. J Comm Med. 2009;5(2):5-8.

34. Chennaveerappa PK, Siddharam SM, Halesha BR, Vittal BG, Jayashree N. Treatment outcome of tuberculosis patients registered at dots centre in a teaching hospital, south India. Int J Biol Med Res. 2011;2(2):487-9.

Cite this article as: Kundu SS, Sikder R, Dey R, Majumdar KK, Joardar G. Study of socio-demographic and treatment profile and other epidemiological correlates of clients attending revised national tuberculosis control programme clinic in a tertiary hospital of West Bengal, India. Int J Community Med Public Health 2020;7:742-7. 